\title{
Características produtivas e estruturais de genótipos de palma forrageira irrigada em diferentes intervalos de corte
}

\author{
Rocha, R.S. ; Voltolini, T.V. ${ }^{2 @ ~ e ~ G a v a, ~ C . A . T . ~}{ }^{2}$
}

'Mestrado em Ciência animal. Universidade Federal do Vale. São Francisco. Brasil.

${ }^{2}$ Embrapa Semiárido. Petrolina/PE. Brasil.

\section{PALAVRAS-CHAVE ADICIONAIS}

Índice de área de cladódio.

Nopalea sp.

Opuntia sp.

\section{RESUMO}

A palma forrageira, recebendo aporte adicional de água, pode se constituir em alternativa alimentar para os rebanhos da região semiárida brasileira, entretanto são escassas as informações sobre as respostas produtivas e estruturais dos genótipos, assim como do intervalo de cortes da planta. Esta pesquisa teve o objetivo de avaliar as características produtivas e estruturais de genótipos de palma forrageira em diferentes intervalos de corte. $O$ delineamento experimental foi em blocos completos casualizados com parcelas subdivididas tendo os genótipos dispostos nas parcelas e os intervalos de corte nas subparcelas, com quatro repetições por tratamento, totalizando 48 unidades experimentais. $O$ experimento foi realizado no período de maio de 2014 a setembro de 2015, com três genótipos de palma forrageira, a orelha de elefante mexicana (OEM) (Opuntia stricta (Haw.) Haw.), IPA 20 (Opuntia ficus indica (Mill)) e a miuda (Nopalea cochenillifera Salm. Dyck) e intervalos de corte de 4, 8, 12 e 16 meses após o plantio. A OEM aos 16 meses apresentou maior massa de forragem (t de matéria seca/ha e matéria verde/ha) em comparação com a miuda e IPA 20 nos diferentes intervalos de corte, tendo ainda maior taxa de acúmulo de forragem e melhor eficiência de uso da água. A miuda teve maior número de cladódios e cladódios mais leves. A OEM juntamente com a miuda apresentaram maiores índices de área de cladódio a partir de oito meses após o plantio comparada à IPA 20. Os genótipos assim como o intervalo de corte afetam as características produtivas e estruturais da palma forrageira.

Productive and structural characteristics of genotypes of irrigated spineless cactus in different cutting intervals

\section{SUMMARY}

The spineless cactus receiving additional water may constitute alternative food for the flocks of the Brazilian semiarid; however, the information about structural and productive responses of genotypes, as well as the cutting intervals are scarce. This research aimed to evaluate the productive and structural characteristics of genotype at different cutting intervals. The experimental design was a randomized block with split plot (genotypes in the plots and cutting intervals in the subplots), with four replicates per treatment, totaling 48 experimental units. The experiment was conducted from May 2014 to September 2015, with three genotypes of cactus, the orelha de elefante mexicana (OEM) (Opuntia stricta (Haw.) Haw.) IPA 20 (Opuntia ficus indica (Mill.) and miuda (Nopalea cochenillifera Salm. Dyck) and at a cutting interval of $4,8,12$ and 16 months after planting. The OEM at 16 months presented greater forage mass (t dry matter/ha and green matter/ha) compared to the miuda and IPA 20 at the different cut intervals, with a greater rate of forage accumulation rate and better water use efficiency. Miuda had more and lighter cladodes. The OEM together with miuda presented greater cladode area index from eight months after planting compared to IPA 20. The genotypes as well as the interval of cuts affect the productive and structural characteristics of spineless cactus.

\section{INTRODUÇÃO}

A palma forrageira (Opuntia sp. e Nopalea sp.) é uma planta que possui capacidade de adaptação em regiões áridas e semiáridas, tolerando condições de altas temperaturas e solos diversos (FAO, 2001). Esta planta tem seu crescimento vegetativo relacionado a características climáticas como a precipitação pluvial, umidade relativa do ar e ao conteúdo de água no solo em decorrência dos principais processos fisiológicos e bioquímicos dependerem da água, a exemplo da fotossíntese, respiração, transpiração e absorção de nutrientes (Sampaio et al., 2005). Portanto, os elementos do clima são fundamentais para potencializar o acúmulo de biomassa nesta planta. De acordo com Nobel (2001), o crescimento da palma está relacionado à ocorrência de 400 a $800 \mathrm{~mm}$ anuais de chuva. 
Porém, nos últimos anos, na região semiárida do Brasil e, especificamente no Sertão do São Francisco-BA e no Submédio do São Francisco-PE, os índices pluviométricos foram muito próximos ou inferiores a $400 \mathrm{~mm}$ anuais. No município de Juazeiro/BA, a precipitação pluvial anual variou de 243,3 a 490,9 mm de 2010 a 2014, volumes estes que podem ser considerados insuficientes para a planta e que podem restringir o cultivo e a exploração deste recurso forrageiro como alternativa alimentar para os rebanhos (Rocha, 2016).

Por outro lado, estudos recentes têm demonstrado que o aporte adicional de água para a palma pode ser uma estratégia interessante para o estabelecimento do palmal e aumento da produtividade (Rego et al., 2014; Queiroz et al., 2015). Esta prática baseia-se na elevada eficiência de uso de água desta planta, que por sua vez possui o metabolismo ácido das crassuláceas (MAC) como via para a biossíntese de carboidratos a partir da fotossíntese (Silva et al., 2014a; Queiroz et al., 2015).

Entretanto, a prática de fornecimento de água, por meio da irrigação, pode promover alterações na dinâmica de crescimento da planta em relação à palma cultivada em sequeiro e, em consequência, existe a necessidade de gerar novas estratégias de manejo para a palma irrigada. Em condição de dependência de chuva, os cortes na palma são realizados de dois a quatro anos após o plantio (Almeida, 2011), enquanto para a palma irrigada este intervalo pode ser reduzido. $\mathrm{O}$ menor intervalo para o corte da palma é importante para obtenção de alimentos em menor tempo aos rebanhos (Almeida, 2011). Por outro lado, de acordo com Farias et al. (2000) maiores produções de palma podem ser obtidas em intervalos de corte maiores.

Em adição, as características morfológicas dos cladódios assim como as estruturais da planta podem influenciar a fisiologia e o crescimento da palma, afetando a resposta produtiva da cultura. Pinheiro et al. (2014) verificaram que o índice de área de cladódio da palma forrageira possui correlação com as características estruturais como a altura e a largura da planta e, que, por sua vez, pode afetar a produtividade. Portanto, o conhecimento dos efeitos dos intervalos de corte sobre a produção e as características estruturais da palma forrageira pode ser decisivo para o aumento da eficiência produtiva e de uso desta cultura. Deste modo, esta pesquisa teve como objetivo avaliar as características produtivas e estruturais de genótipos de palma forrageira submetidos a irrigação, em quatro intervalos de corte.

\section{MATERIAL E MÉTODOS}

O experimento foi conduzido na Fazenda Agro Curaçá, no município de Curaçá-BA, no território do Sertão do São Francisco. O ensaio experimental foi realizado no período de maio de 2014, momento do plantio, a setembro de 2015, com três genótipos de palma forrageira, sendo orelha de elefante mexicana (OEM) (Opuntia stricta (Haw.) Haw.), IPA 20 (Opuntia ficus indica (Mill.) e a palma Miúda (Nopalea cochenillifera Salm Dyck). Como material de plantio foram utilizados cladódios com seis meses de idade após a rebrota, retirados da porção intermediária da planta original, que passaram após o corte por período de 15 dias para a cura e cicatrização a sombra. O plantio foi efetuado com espaçamento de 0,10 m entre plantas, no método dominó com raquetes paralelas umas às outras, e espaçamento de 2,0 m entre ruas (linhas de plantio), compreendendo densidade equivalente a 50000 plantas por hectare.

Os tratamentos consistiram de quatro intervalos de corte, aos 4, 8, 12 e 16 meses após o plantio, além dos três genótipos de palma forrageira. $\mathrm{O}$ delineamento experimental foi em blocos casualizados com parcelas subdivididas, tendo os genótipos dispostos nas parcelas e os intervalos de corte como os secundários (subparcelas), com quatro repetições por tratamento, totalizando 48 unidades experimentais. Durante o ensaio experimental, nos intervalos com 12 e 16 meses, foi realizado apenas um corte da planta no período todo, enquanto no de intervalo de oito meses foram realizados dois cortes e no de quatro meses, quatro cortes.

Para cada um dos três genótipos foram plantadas 1200 mudas de palma (cladódios), distribuídas em três linhas de plantio com 400 mudas cada tendo $40 \mathrm{~m}$ de comprimento, totalizando nove linhas. Em cada bloco foram plantadas 100 mudas por genótipo, com 25 para cada intervalo de corte. Das 25 plantas, as cinco centrais foram consideradas como a área útil onde foram efetuados os cortes.

Antes do plantio foram coletadas três amostras de solo, representativas da área do experimento. A análise do solo foi realizada no laboratório de Solos e Tecidos Vegetais da Embrapa Semiárido - PetrolinaPE. O solo da área é classificado como Vertissolo e os resultados médios das análises foram: condutividade elétrica $=0,98 \mathrm{dS} / \mathrm{m}$; $\mathrm{pH}\left(\mathrm{H}_{2} 0\right.$ 1:2,5) = 6,00; matéria orgânica $=3,73 \mathrm{~g} / \mathrm{kg}$ de matéria orgânica, $\mathrm{P}=3,96 \mathrm{mg}$ / $\mathrm{dm}^{3} ; \mathrm{K}=0,25 \mathrm{cmolc} / \mathrm{dm}^{3}, \mathrm{Na}=1,09 \mathrm{cmolc} / \mathrm{dm}^{3} ; \mathrm{Ca}=$ $8,07 \mathrm{cmolc} / \mathrm{dm}^{3} ; \mathrm{Mg}=6,70 \mathrm{cmolc} / \mathrm{dm}^{3} ; \mathrm{H}+\mathrm{Al}=1,80$ cmolc $/ \mathrm{dm}^{3}$; soma de bases $=16,10 \mathrm{cmolc} / \mathrm{dm}^{3}$; capacidade de troca catiônica $=17,87 \mathrm{cmolc} / \mathrm{dm}^{3}$; saturação de bases $=86,43 \%, \mathrm{Cu}=3,87 \mathrm{mg} / \mathrm{dm}^{3} ; \mathrm{Fe}=99,20 \mathrm{mg} /$ $\mathrm{dm}^{3} ; \mathrm{Mn}=54,90 \mathrm{mg} / \mathrm{dm}^{3} ; \mathrm{Zn}=1,14 \mathrm{mg} / \mathrm{dm}^{3}$.

As adubações foram efetuadas ao longo do ciclo de cultivo, realizadas com aplicações mensais por hectare de $30 \mathrm{~kg}$ de ureia, $14 \mathrm{~kg}$ de mono-amônio fosfato (MAP) e $100 \mathrm{~kg}$ de sulfato de potássio, com base nas análises de solo e na extração de N, P e K estimada para a produtividade $500 \mathrm{t}$ de MV (matéria verde)/ ha/ano, da ordem de $\mathrm{N}=180 \mathrm{~kg}, \mathrm{P}=30 \mathrm{~kg}, \mathrm{~K}=520 \mathrm{~kg}$ e Ca $=243 \mathrm{~kg}$. Com a ocorrência de chuvas a aplicação de adubo foi realizada a lanço, enquanto no período seco o fertilizante foi aplicado por fertirrigação.

Foi realizado o acompanhamento das condições meteorológicas durante o período do experimento por meio da Estação Agrometeorológica da Embrapa Semiárido, localizada no distrito do Mandacaru no município de Juazeiro-BA $\left(09^{\circ} 24^{\prime} \mathrm{S} 40^{\circ} 26^{\prime} \mathrm{W}\right)$, com dados coletados do site (http:/ / www.cpatsa.embrapa.br:8080/ index.php?op=eamand). No período experimental, a precipitação pluvial foi $443,3 \mathrm{~mm}$, as temperaturas média, máxima e mínima foram $26,27^{\circ} \mathrm{C}, 33,15^{\circ} \mathrm{C}$ e $20,62^{\circ} \mathrm{C}$, respectivamente e as umidades relativas do ar média e mínima foram 62,00\% e 37,76\% (figura 1). 
A irrigação realizada foi por gotejamento, complementar à precipitação pluvial, efetuada a cada 15 dias a partir da última chuva ocorrida. Em média o tempo de aplicação de água teve duração de quatro horas, com lâmina aplicada de $16,4 \mathrm{~mm}$ a cada 15 dias $(32,8 \mathrm{~mm} /$ mês), considerando 0,52 de coeficiente da cultura (Kc) (Queiroz et al., 2015). A vazão da fita gotejadora foi 4,1 $\mathrm{mm} / \mathrm{h} /$ metro linear com tubogotejador de parede fina e gotejador plano. A aplicação de água iniciava-se ao final da tarde. No período do experimento foram aplicados 295,2 mm com a irrigação, somando-se aos 443,3 mm de precipitação, totalizando 738,5 mm (figura 2).

Foram realizadas no período quatro capinas manuais, sempre próximas aos períodos de corte da planta. Para o controle de pragas, com a ocorrência da cochonilha de escama (Diaspis echinocacti) foi realizada a pulverização em bomba costal com capacidade de 20 L, do inseticida Fastac @ 100 SC (Alfacipertrapina) na dosagem de $20 \mathrm{~mL}$ por bomba, realizando-se de três aplicações no período. Não foi observada a ocorrência de outras pragas e de doenças nas plantas.

Para a determinação da massa de forragem (MF) ( $\mathrm{kg}$ de MV/planta), o corte de cada planta foi realizado deixando-se apenas a raquete base, pesando-se todo o material cortado. Com o número de cladódios e o peso do material cortado, obteve-se o peso médio do cladódio. Posteriormente, foi retirada amostra da porção central de cladódios da primeira ordem, a qual foi encaminhada ao Laboratório de Nutrição Animal da Embrapa Semiárido em Petrolina/PE para a determinação dos teores de MS, realizando-se a pré-secagem em estufa de circulação forçada de ar a $65^{\circ} \mathrm{C}$ por 72 horas e posteriormente submetendo-se a amostra à secagem definitiva a $105^{\circ} \mathrm{C}$ por 12 horas, de acordo com a metodologia descrita por Silva e Queiroz (2002). A MF dada em $\mathrm{kg}$ de MV/planta foi multiplicada pelo teor de MS da planta para determinação dos valores de MF em kg de MS/planta. Este valor multiplicado por 50.000 plantas foi utilizado para estimar a MF em kg de MS/ha. A taxa de acúmulo de forragem (TAF) ( $\mathrm{g}$ de $\mathrm{MV} /$ planta/dia) foi calculada pela divisão da MF (kg de MV/planta) /1 000, pelo intervalo de corte (dias).

A eficiência de uso da água (EUA) ( $\mathrm{kg}$ de $\mathrm{MS} / \mathrm{mm}$ ) foi obtida pela divisão da MF ( $\mathrm{kg}$ de MS/ha) pelo volume total de água $(\mathrm{mm})$ somando-se a precipitação e a irrigação aplicada (figura 2), em cada um dos intervalos de corte.

$\mathrm{Na}$ ocasião da colheita foram mensuradas as variáveis: altura $(\mathrm{cm})$, largura $(\mathrm{cm})$ e número de cladódios por planta, bem como o peso do cladódio ( $\mathrm{g}$ de MS), comprimento (cm), largura (cm) e área do cladódio $\left(\mathrm{cm}^{2}\right)$, além do índice de área de cladódio (IAC). Estas medidas foram tomadas em cinco plantas da área útil da parcela. Para a mensuração da altura e largura da planta foi utilizada fita métrica, considerou-se o comprimento desde a extremidade do artículo mais alto até o solo. A largura da planta foi medida pelas extremidades laterais da planta. Em seguida foi realizada a contagem do número de cladódios. Nos cladódios, também com fita métrica, foram individualmente medidos o comprimento (tomada de uma extremidade à outra do artículo) e a largura (medida no meio do cladódio) para posterior determinação da área e do índice de área de cladódio.

Para cada genótipo foi estimada a área do cladódio $\left(\mathrm{cm}^{2}\right)$ usando-se as seguintes equações: IPA $20=$ 0,7318(1-exp(-0,0034.cc.lc))/0,0034; OEM = 0,7086(1$\exp (-0,000045765$.cc.lc) )/0,000045765; Miúda = 0,7198. cc.lc, em que cc = comprimento do cladódio $(\mathrm{cm})$ e lc $=$ largura do cladódio (cm) (SILVA et al., 2014b). Já, o índice de área do cladódio $\left(\mathrm{m}^{2} / \mathrm{m}^{2}\right)$ foi calculado como se

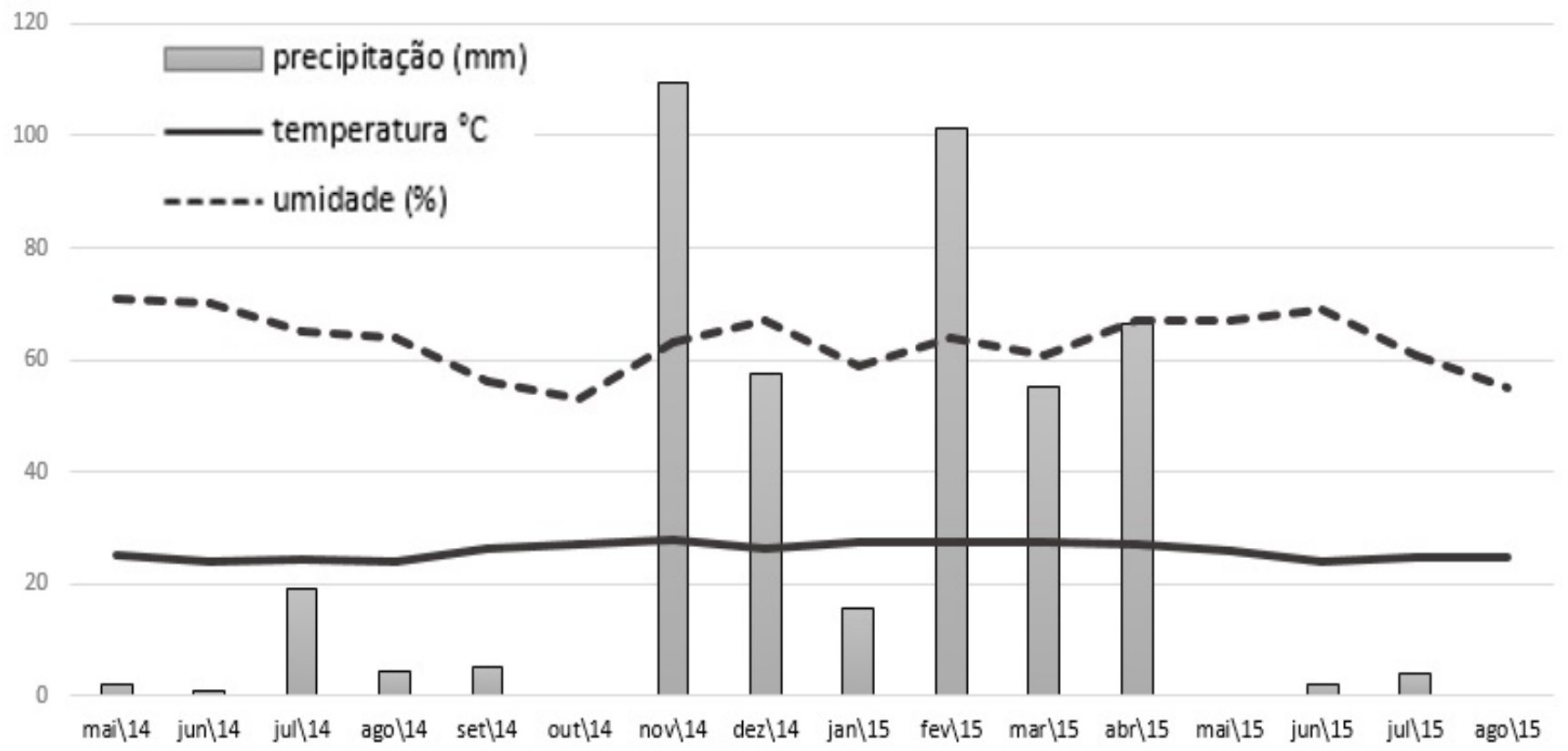

Figura 1. Dados meteorológicos durante o período experimental. Fonte: Estação Agrometeorológica da Embrapa Semiárido no distrito de Mandacaru, município de Juazeiro/BA (Meteorological data during the experimental period. Source: Embrapa Semiarid Agrometeorological Station in the district of Mandacaru, municipality of Juazeiro/BA). BA=Bahia 


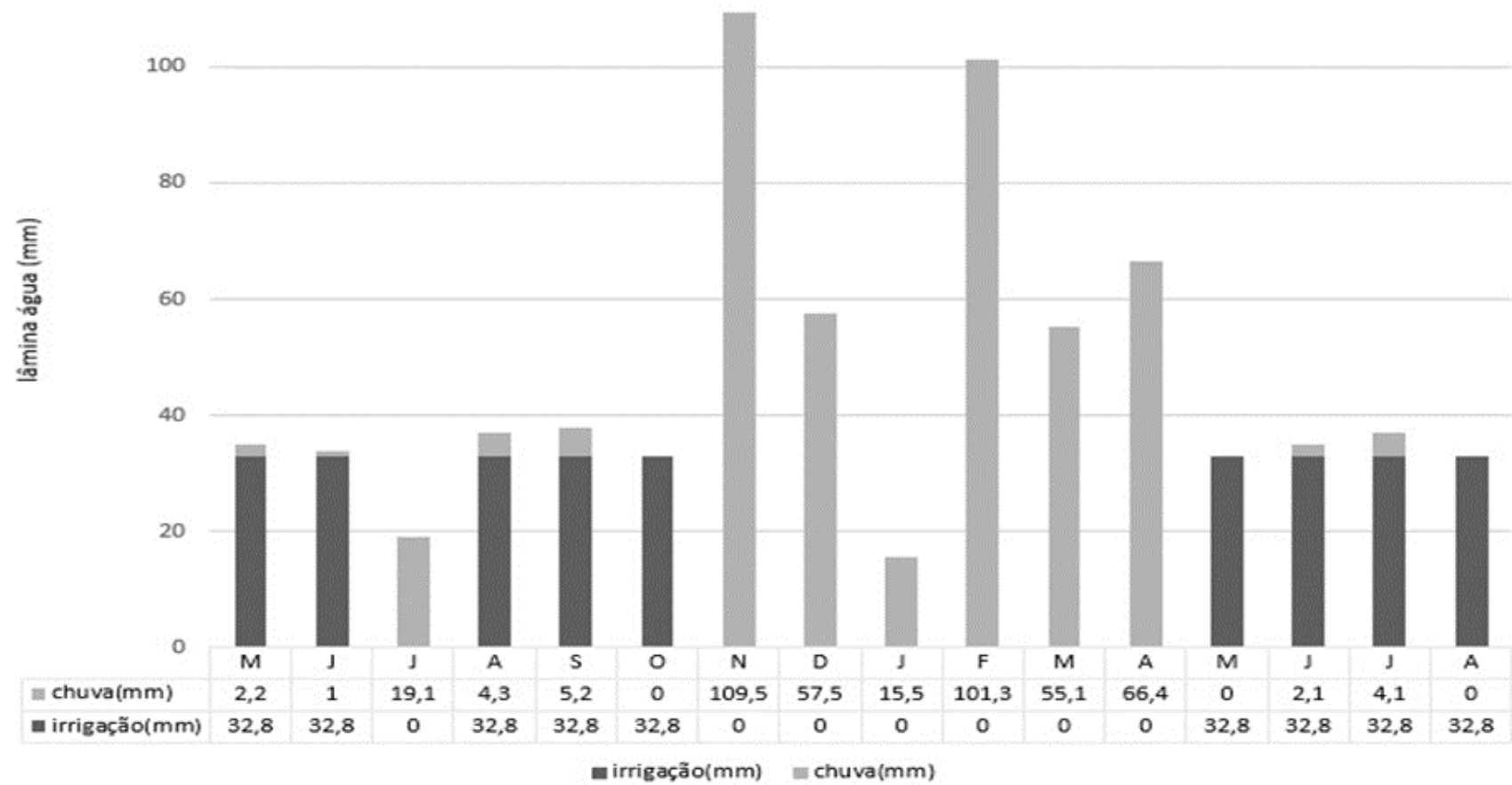

Figura 2. Volume de água aplicado pela irrigação e obtido pela precipitação pluvial durante o período experimental (Water volume applied by irrigation and obtained by rainfall during the experimental period).

segue: (área de cladódio $\left(\mathrm{cm}^{2}\right)$ x número de cladódios por planta)/ 10.000/ (E1 x E2), sendo 10.000 o fator de conversão de $\mathrm{cm}^{2}$ para $\mathrm{m}^{2}$ e E1 x E2 é o espaçamento entre fileiras e entre plantas, respectivamente. Com o número de cladódios e o peso do material cortado, obteve-se o peso médio do cladódio.

Os dados obtidos no experimento foram submetidos à verificação da distribuição normal, presença de outliers e, posteriormente, à análise de variância pelo teste de Tukey. As análises estatísticas foram realizadas utilizando-se o Statistical Analyses System - SAS (2002), considerando como significativos valores de probabilidade inferiores a $5 \%(\mathrm{p}<0,05)$.

\section{RESULTADOS E DISCUSSÃO}

O comprimento, a largura e a área dos cladódios foram diferentes para os três genótipos de palma forrageira avaliados (tabela I), não sendo verificada interação e os intervalos de corte. Por outro lado, foi observada interação entre os genótipos e os intervalos de cortes para as MF ( $t$ de MV/ha e $t$ de MS/ha), teor de MS, TAF, EUA (tabela II), altura e largura da planta, número de cladódios por planta, peso do cladódio e IAC (tabela III).

A maior MF ( $t$ de $M V /$ ha) foi obtida para a OEM aos 16 meses após o plantio, seguida por este mesmo genótipo aos 12 meses, enquanto as menores MF foram apresentadas pelas palmas Miuda e IPA 20 aos quatro meses após o plantio. Houve aumento da MF para os três genótipos avaliados com o avanço do intervalo de cortes (tabela II). Respostas semelhantes foram encontradas para a massa de forragem em $\mathrm{t}$ de MS/ha, em que a OEM aos 16 meses e, em sequência, aos 12 meses pós-plantio tiveram os maiores valores, ao passo que a palma Miuda aos quatro meses apresentou a menor MF sendo semelhante a IPA 20 neste mesmo intervalo de corte (tabela II).

As maiores MF obtidas com o avanço no intervalo de corte eram esperadas e são justificadas pelo aporte contínuo de água e de nutrientes às plantas ao longo de todo o ciclo de cultivo. Mesmo no corte realizado aos quatro meses após o plantio os genótipos de palma-forrageira apresentaram valores consideráveis de MF. A produção precoce de palma é importante para proporcionar alimentos aos rebanhos já no primeiro período seco após a implantação da cultura. Normalmente, em áreas dependentes de chuva o corte da palma se dá de dois a quatro anos após o plantio (Almeida, 2011). As MF ( $t$ de MV/ha e $t$ de MS/ha) obtidas na presente pesquisa foram elevadas, especialmente a apresentada pela OEM e podem ser justificadas pela alta taxa de acúmulo de forragem apresentada pelas plantas associada à alta densidade de cultivo, da ordem de 50.000 plantas/ha.

O cultivo de plantas forrageiras em condições de dependência de chuva no semiárido apresenta anualmente sazonalidade na produção de forragem, causada principalmente por queda na precipitação pluviométrica e também por outros fatores climáticos como a temperatura. A estratégia de fornecer água de forma artificial à palma forrageira fez com que não ocorresse redução na MF dos genótipos Miúda, OEM e IPA 20 ao longo dos 16 meses de cultivo.

Os valores de MF observados na presente pesquisa foram superiores aos relatados por Queiroz et al. (2015) 
Tabela I. Características estruturais de genótipos de palma forrageira irrigada no município de Curaçá/BA (Structural characteristics of genotypes of irrigated spineless cactus in Curaçá/BA).

\begin{tabular}{lccccc}
\hline Variável & Miuda & OEM & IPA 20 & EPM & p \\
\hline Comprimento do cladódio, cm & $23,21^{\mathrm{b}}$ & $25,66^{\mathrm{a}}$ & $27,22^{\mathrm{a}}$ & 0,54 & 0,0001 \\
Largura do cladódio, $\mathrm{cm}$ & $9,78^{\mathrm{c}}$ & $21,36^{\mathrm{a}}$ & $14,43^{\mathrm{b}}$ & 0,31 & 0,0001 \\
Área do cladódio, $\mathrm{cm}^{2}$ & $163,39^{\mathrm{b}}$ & $383,55^{\mathrm{a}}$ & $158,62^{\mathrm{b}}$ & 11,37 & 0,0001 \\
\hline
\end{tabular}

Médias seguidas de mesma letra minúscula na linha não diferem entre si pelo teste de Tukey a $5 \%$ de probabilidade $(p<0,05)$. EPM $=$ erro padrão da média; $\mathrm{P}=$ probabilidade; $\mathrm{OEM}=$ orelha de elefante mexicana.

Tabela II. Efeito da interação entre genótipos e intervalos de corte sobre as características produtivas, teor de matéria seca (MS) e eficiếncia de uso da água da palma forrageira irrigada (Effect of interaction between genotypes and cutting intervals on productive characteristics, dry matter levels (DM) and water use efficiency of irrigated spineless cactus).

\begin{tabular}{|c|c|c|c|c|c|c|c|}
\hline \multicolumn{8}{|c|}{ Massa de forragem, $\mathrm{t}$ de $\mathrm{MV} / \mathrm{ha}$} \\
\hline \multirow{2}{*}{$\begin{array}{l}\text { Icorte } \\
\text { (meses) }\end{array}$} & \multicolumn{3}{|c|}{ Genótipo } & \multicolumn{3}{|c|}{$\mathrm{p}$} & \multirow{2}{*}{$C V, \%$} \\
\hline & Miuda & OEM & IPA 20 & G & Icorte & Gxlcorte & \\
\hline 4 & $102,50^{\mathrm{h}}$ & $208,88^{9}$ & $142,13^{h}$ & \multirow{4}{*}{$<0,0001$} & \multirow{4}{*}{$<0,0001$} & \multirow{4}{*}{$<0,0001$} & \multirow{4}{*}{4,86} \\
\hline 8 & $218,25^{\mathrm{fg}}$ & $323,75^{e}$ & $252,63^{f}$ & & & & \\
\hline 12 & $315,50^{e}$ & $566,00^{b}$ & $376,25^{d}$ & & & & \\
\hline 16 & $383,75^{d}$ & $763,50^{\mathrm{a}}$ & $426,75^{c}$ & & & & \\
\hline \multicolumn{8}{|c|}{ Massa de forragem, $\mathrm{t}$ de MS/ha } \\
\hline \multirow{2}{*}{$\begin{array}{l}\text { Icorte } \\
\text { (meses) }\end{array}$} & \multicolumn{3}{|c|}{ Genótipo } & \multicolumn{3}{|c|}{$\mathrm{p}$} & \multirow{2}{*}{$C V, \%$} \\
\hline & Miuda & OEM & IPA 20 & G & Icorte & Gxlcorte & \\
\hline 4 & $9,78^{9}$ & $20,07^{f}$ & $12,06^{\mathrm{fg}}$ & \multirow{4}{*}{$<0,0001$} & \multirow{4}{*}{$<0,0001$} & \multirow{4}{*}{$<0,0001$} & \multirow{4}{*}{9,60} \\
\hline 8 & $20,35^{f}$ & $28,47^{\text {ef }}$ & $29,72^{\mathrm{e}}$ & & & & \\
\hline 12 & $31,34^{\mathrm{e}}$ & $75,99^{b}$ & $42,64^{\mathrm{d}}$ & & & & \\
\hline 16 & $46,06^{\text {cd }}$ & $91,74^{\mathrm{a}}$ & $52,00^{c}$ & & & & \\
\hline \multicolumn{8}{|c|}{ Teor de MS, g/kg } \\
\hline \multirow{2}{*}{$\begin{array}{l}\text { Icorte } \\
\text { (meses) }\end{array}$} & \multicolumn{3}{|c|}{ Genótipo } & \multicolumn{3}{|c|}{$\mathrm{p}$} & \multirow{2}{*}{$\mathrm{CV}, \%$} \\
\hline & Miuda & OEM & IPA 20 & G & Icorte & Gxlcorte & \\
\hline 4 & $95,50^{c}$ & $96,10^{\mathrm{b}}$ & $84,90^{c}$ & \multirow{4}{*}{$<0,03$} & \multirow{4}{*}{$<0,0001$} & \multirow{4}{*}{$<0,0001$} & \multirow{4}{*}{8,33} \\
\hline 8 & $93,30^{c}$ & $88,00^{c}$ & $117,70^{\mathrm{ab}}$ & & & & \\
\hline 12 & $99,30^{\mathrm{b}} \mathrm{C}$ & $134,20^{\mathrm{a}}$ & $113,40^{\mathrm{a}}$ & & & & \\
\hline 16 & $120,00^{\mathrm{a}}$ & $120,60^{\mathrm{a}}$ & $124,10^{\mathrm{a}}$ & & & & \\
\hline \multicolumn{8}{|c|}{ Taxa de acúmulo de forragem, g de MS/planta/dia } \\
\hline \multirow{2}{*}{$\begin{array}{l}\text { Icorte } \\
\text { (meses) }\end{array}$} & \multicolumn{3}{|c|}{ Genótipo } & \multicolumn{3}{|c|}{$\mathrm{p}$} & 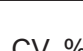 \\
\hline & Miuda & OEM & IPA 20 & G & Icorte & Gxlcorte & 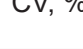 \\
\hline 4 & $1,63^{d}$ & $3,35^{\mathrm{b}}$ & $2,01^{\text {cd }}$ & & & & \\
\hline 8 & $1,70^{\mathrm{d}}$ & $2,37^{c}$ & $2,48^{\mathrm{c}}$ & - $\cap \cap 0 \cap 1$ & - $\cap 0 n n 1$ & - $\cap 0 \cap 01$ & 015 \\
\hline 12 & $1,74^{\mathrm{d}}$ & $4,22^{\mathrm{a}}$ & $2,37^{c}$ & $<0,0001$ & $<0,0001$ & $<0,0001$ & 8,15 \\
\hline 16 & $1,92^{\mathrm{d}}$ & $3,83^{\mathrm{ab}}$ & $2,21^{c}$ & & & & \\
\hline
\end{tabular}

Eficiência de uso da água, $\mathrm{kg}$ de $\mathrm{MS} / \mathrm{mm}$ de água

\begin{tabular}{|c|c|c|c|c|c|c|c|}
\hline \multirow{2}{*}{$\begin{array}{l}\text { Icorte } \\
\text { (meses) }\end{array}$} & \multicolumn{3}{|c|}{ Genótipo } & \multicolumn{3}{|c|}{$\mathrm{p}$} & \multirow{2}{*}{$\mathrm{CV}, \%$} \\
\hline & Miuda & OEM & IPA 20 & G & Icorte & Gxlcorte & \\
\hline 4 & $78,31^{d}$ & $160,59^{a}$ & $96,47^{c}$ & \multirow{4}{*}{$<0,0001$} & \multirow{4}{*}{$<0,0001$} & \multirow{4}{*}{$<0,0001$} & \multirow{4}{*}{8,12} \\
\hline 8 & $56,10^{\text {ef }}$ & $78,47^{d}$ & $81,91^{\mathrm{cd}}$ & & & & \\
\hline 12 & $52,13^{f}$ & $126,42^{b}$ & $70,93^{d}$ & & & & \\
\hline 16 & $62,38^{\text {ef }}$ & $124,22^{b}$ & $71,76^{\text {de }}$ & & & & \\
\hline
\end{tabular}

Médias seguidas por mesma letra não diferem entre si pelo teste de Tukey a $5 \%$ de probabilidade $(p<0,05)$. MV= matéria verde; OEM= orelha de elefante mexicana; G = genótipo; Icorte = intervalo de cortes; Gxlcorte = interação entre genótipo e intervalo de cortes; CV= coeficiente de variação; $p=$ probabilidade. 
também em condição irrigada e em semelhante idade de corte, uma vez que estes autores obtiveram $0,52 \mathrm{~kg}$ de MS/planta para a OEM cortada aos 380 dias após o plantio, enquanto nesta pesquisa a OEM cortada aos 12 meses apresentou 1,52 kg de MS/planta, o que pode estar relacionado à nutrição das plantas pelo fornecimento de fertilizantes via fertirrigação e ao manejo de fornecimento de água, aplicando-se maior volume de água.

A maior MF (t de MV/ha) da OEM desde os 4 meses após o plantio em relação a Miuda e a IPA 20 pode ter ocorrido pela maior área de cladódio, que por sua vez é importante para o crescimento da planta, já que com maior área a planta pode apresentar maiores taxas fotossintéticas. De acordo com Ramírez-Tobias et al. (2010) cladódios menores propiciam menor área de absorção de $\mathrm{CO}_{2}$ pela planta. Além disto, Queiroz et al. (2015) afirmam que a OEM possui elevada eficiência de uso da água em relação a outros genótipos de palma forrageira. Maior MF da OEM em comparação com a Miúda e a IPA Sertânia também foi verificada por Silva et al. (2015) que relacionaram estes achados ao maior índice de área de cladódio (IAC) deste genótipo em relação aos demais.

Na comparação entre os genótipos, os resultados divergiram dos apresentados por Cavalcante et al. (2014) que avaliaram as respostas produtivas de genótipos de palma forrageira e verificaram maior produtividade para a Miúda (Nopalea) em relação a Gigante e Redonda (Opuntia). Por outro lado, Silva et al. (2015) observaram melhor resposta produtiva da OEM (Opuntia) quando comparada com a IPA Sertânia e com a Miúda (Nopalea), resultado semelhante ao encontrado na presente pesquisa, em que a OEM teve maior MF que a Miúda. Ramírez-Tobias et al. (2010) também verificaram diferenças nas respostas produtivas de genótipos de palma forrageira, sobretudo quanto aos diferentes gêneros, verificando menor produtividade da Nopalea em relação a Opuntia e atribuíram estes resultados ao menor tamanho dos cladódios da Nopalea.

A palma Miúda é apontada como de pior adaptação a localidades com menores precipitações e temperatura noturna elevada (Silva et al., 2015). No entanto, nesta pesquisa, as respostas produtivas deste genótipo se assemelharam às produtividades encontradas em regiões consideradas como de melhor adaptação para ela, sugerindo que o fornecimento de água minimizou os impactos da temperatura na produção da planta. No entanto, quando comparada aos outros genótipos (OEM e IPA 20) utilizados nesta pesquisa, a Miúda apresentou menor MF (t de MV/ha), sobretudo a partir dos 12 meses. Scalisi et al. (2016) relataram que em condições em que a palma encontra-se em déficit hídrico, a umidade do solo exerce maior influência que a temperatura na espessura dos cladódios, atribuindo portanto maior importância à água disponibilizada do que à temperatura na produção da planta. A espessura dos cladódios é importante para a capacidade fotossintética e de armazenamento de água.

Comparando os genótipos OEM e IPA 20, ambos do gênero Opuntia, as diferenças em MF podem ser atribuídas ao menor número de cladódios e área de cladódio por planta além de menor índice de área de cladódio (IAC) da IPA 20, em que estas características estão associadas à capacidade fotossintética da planta.

$\mathrm{Na}$ taxa de acúmulo de forragem (TAF) (g de MV / planta/dia), os maiores valores foram encontrados para a OEM aos 12 meses, cujo resultado assemelhou-se ao observado aos 16 meses. Por outro lado, a Miuda de oito a 16 meses apresentou TAF menores que a IPA 20 e OEM (tabela II). A TAF representa o balanço entre o crescimento e a senescência da planta num determinado período, em que no caso da palma corresponde ao crescimento em cada um dos intervalos de corte. A maior TAF da OEM aos 12 meses, com resultado semelhante aos 16 meses indica que o corte da planta nos menores intervalos (4 e 8) pode resultar em menor produtividade, possivelmente em razão da planta aumentar o número e o peso dos cladódios ao longo do período em crescimento, aumentando em consequência a área e o IAC que contribuem para a fotossíntese. Para a Miuda e a IPA 20, o corte efetuado de quatro a 16 meses promoveu semelhante TAF.

Segundo, Nobel (1991) o crescimento da palma está relacionado com o IAC e a máxima produtividade é obtida entre 4 a 5 ou 2 a 2,5, ao considerar que apenas $50 \%$ do cladódio está contribuindo para a fotossíntese. Valores menores ou maiores a estes podem proporcionar menor radiação fotossinteticamente ativa às plantas diminuindo a captação de $\mathrm{CO}_{2}$ e, em consequência, promover menor crescimento. No entanto, o IAC é dependente de diversos fatores como o espaçamento e a densidade de cultivo.

$\mathrm{Na}$ presente pesquisa, o IAC aumentou para os três genótipos nos maiores intervalos de corte (tabela III), mas para a IPA 20 o crescimento foi inferior ao apresentado pelos demais, possivelmente em razão do menor número de cladódios da IPA 20. O IAC da palma Miúda e OEM aos 16 meses após o plantio foi dentro da faixa considerada ótima por Nobel (1991), para o máximo crescimento da palma, enquanto na IPA 20 não chegou a 1. Este baixo valor de IAC pode ser o fator que contribuiu para as menores TAF da IPA 20. De acordo com Ramírez-Tobias et al. (2010) a palma apresenta três fases de crescimento, com cerca de 40 dias uma fase chamada Lag, com 200 dias a fase de crescimento exponencial tendo aumento do sistema radicular e alta captação de $\mathrm{CO}_{2} \mathrm{e}$, posteriormente, a fase de estabilização.

Para as palmas Miúda e OEM, nesta pesquisa, até os 16 meses parece não ter atingido a fase de estabilização do crescimento da planta, o que também está de acordo com os resultados apresentados por Farias et al. (2000) que avaliaram frequências de corte em palma forrageira cultivada em dependência da chuva (dois e quatro anos de intervalo para o corte) e verificaram maiores produções para a palma cortada com intervalo de quatro anos, quando foram conservados os artículos primários. Quando o corte foi realizado conservando-se os artículos secundários foi obtida semelhante produção de forragem nas diferentes frequências de corte.

Outro fator que pode ter contribuído para a maior TAF da OEM e IPA 20 em comparação com a Miuda é o crescimento secundário com aumento dos teores de 
matéria seca, das porções fibrosas e da lignificação da planta. Em média, considerando os quatro intervalos de cortes a OEM teve 100,97 $\mathrm{g} / \mathrm{kg}$ de MS, a IPA apresentou 110,00, enquanto a Miuda teve 102,00 g/ kg de MS. Nesta pesquisa, os teores de MS aumentaram nos maiores intervalos de corte para os três genótipos (tabela II). Com o maior intervalo de corte e a continuidade no crescimento da planta os cladódios das primeiras ordens de crescimento podem ter envelhecido, com aumento de porção fibrosa e de lignina, incrementando os teores de MS da planta. Este crescimento da planta com o envelhecimento e o fortalecimento dos cladódios da base se dá para suportar a geração de novas ordens de cladódios.

A OEM aos quatro meses teve maior EUA, seguida por este mesmo genótipo aos 12 e 16 meses (tabela II). A OEM apresentou no corte realizado aos oito meses após o plantio a menor EUA em relação aos demais períodos, o que pode estar associado a este intervalo ter apresentado a ocorrência de chuvas promovendo menor uso da irrigação por gotejamento. A maior ocorrência de chuvas e o menor uso da água da chuva pelas plantas diminui o uso da água em relação à irrigação por gotejamento. As maiores EUA da OEM e na se-

Tabela III. Efeito da interação entre genótipos e intervalos de corte sobre as características estruturais da palma forrageira irrigada (Effect of interaction between genotypes and cutting intervals on structural characteristics of irrigated spineless cactus).

\begin{tabular}{|c|c|c|c|c|c|c|c|}
\hline \multicolumn{8}{|c|}{ Altura da planta, $\mathrm{cm}$} \\
\hline \multirow{2}{*}{$\begin{array}{l}\text { Icorte } \\
\text { (meses) }\end{array}$} & \multicolumn{3}{|c|}{ Genótipo } & \multicolumn{3}{|c|}{$p$} & \multirow{2}{*}{$C V, \%$} \\
\hline & Miuda & OEM & IPA 20 & G & Icorte & Gxlcorte & \\
\hline 4 & $50,54^{i}$ & $51,89^{\mathrm{hi}}$ & $57,43^{\text {h }}$ & \multirow{4}{*}{$<0,0001$} & \multirow{4}{*}{$<0,0001$} & \multirow{4}{*}{$<0,0001$} & \multirow{4}{*}{4,60} \\
\hline 8 & $74,68^{f}$ & $66,88^{9}$ & $72,10^{f g}$ & & & & \\
\hline 12 & $87,50^{d}$ & $81,50^{\mathrm{e}}$ & $93,25^{\mathrm{c}}$ & & & & \\
\hline 16 & $104,00^{\mathrm{ab}}$ & $98,80^{\text {bc }}$ & $108,60^{\mathrm{a}}$ & & & & \\
\hline \multicolumn{8}{|c|}{ Largura da planta, $\mathrm{cm}$} \\
\hline \multirow{2}{*}{$\begin{array}{l}\text { Icorte } \\
\text { (meses) }\end{array}$} & \multicolumn{3}{|c|}{ Genótipo } & \multicolumn{3}{|c|}{$p$} & \multirow{2}{*}{$\mathrm{CV}, \%$} \\
\hline & Miuda & OEM & IPA 20 & $G$ & Icorte & Gxlcorte & \\
\hline 4 & $55,13^{\text {ef }}$ & $56,73^{\mathrm{e}}$ & $49,98^{f}$ & \multirow{4}{*}{$<0,0002$} & \multirow{4}{*}{$<0,0001$} & \multirow{4}{*}{$<0,006$} & \multirow{4}{*}{5,67} \\
\hline 8 & $71,63^{\text {cd }}$ & $80,48^{c}$ & $65,88^{\text {de }}$ & & & & \\
\hline 12 & $116,75^{\mathrm{a}}$ & $103,60^{b}$ & $96,86^{b}$ & & & & \\
\hline 16 & $109,20^{\text {ab }}$ & $105,45^{\mathrm{ab}}$ & $105,10^{\mathrm{ab}}$ & & & & \\
\hline \multicolumn{8}{|c|}{ Número de cladódios } \\
\hline \multirow{2}{*}{$\begin{array}{l}\text { Icorte } \\
\text { (meses) }\end{array}$} & \multicolumn{3}{|c|}{ Genótipo } & \multicolumn{3}{|c|}{$p$} & \multirow{2}{*}{$C V, \%$} \\
\hline & Miuda & OEM & IPA 20 & G & Icorte & GxIcorte & \\
\hline 4 & $14,29^{d}$ & $8,20^{e f}$ & $5,85^{f}$ & \multirow{4}{*}{$<0,0001$} & \multirow{4}{*}{$<0,0001$} & \multirow{4}{*}{$<0,0001$} & \multirow{4}{*}{11,10} \\
\hline 8 & $34,60^{\mathrm{b}}$ & $14,00^{d}$ & $11,20^{d}$ & & & & \\
\hline 12 & $32,25^{b}$ & $14,90^{\text {cd }}$ & $11,60^{d}$ & & & & \\
\hline 16 & $44,20^{\mathrm{a}}$ & $19,70^{c}$ & $11,05^{\text {de }}$ & & & & \\
\hline \multicolumn{8}{|c|}{ Peso médio do cladódio, kg } \\
\hline Icorte & & Genót & & & $\mathrm{p}$ & & $C V \%$ \\
\hline (meses) & Miuda & OEM & IPA 20 & G & Icorte & Gxlcorte & $\mathcal{U}, \%$ \\
\hline 4 & $0,144^{\mathrm{de}}$ & $0,510^{c}$ & $0,486^{c}$ & & & & \\
\hline 8 & $0,127^{\mathrm{e}}$ & $0,465^{c}$ & $0,452^{\mathrm{c}}$ & & < & $<0 \cap 0 \cap 1$ & 600 \\
\hline 12 & $0,197^{d}$ & $0,761^{a}$ & $0,653^{b}$ & $<0,0001$ & $<0,0001$ & $<0,0001$ & 6,09 \\
\hline 16 & $0,175^{d}$ & $0,777^{a}$ & $0,773^{\mathrm{a}}$ & & & & \\
\hline & & & área de cla & (IAC), $\mathrm{m}^{2} /$ & & & \\
\hline Icorte & & Genót & & & $p$ & & CVo \\
\hline (meses) & Miuda & OEM & IPA 20 & G & Icorte & Gxlcorte & $C V, \%$ \\
\hline 4 & $0,96^{c}$ & $1,26^{c}$ & $0,43^{c}$ & & & & \\
\hline 8 & $2,68^{b}$ & $3,02^{b}$ & $0,84^{c}$ & $<0 \cap 0 \cap 1$ & $<0 \cap 0 \cap 1$ & $<\cap \cap \cap \cap 1$ & 1051 \\
\hline 12 & $2,77^{\mathrm{b}}$ & $2,90^{\mathrm{b}}$ & $0,94^{c}$ & $<0,0001$ & $<0,0001$ & $<0,0001$ & 19,51 \\
\hline 16 & $4,29^{a}$ & $4,13^{\mathrm{a}}$ & $0,94^{c}$ & & & & \\
\hline
\end{tabular}

Médias seguidas por mesma letra não diferem entre si pelo teste de Tukey a $5 \%$ de probabilidade $(p<0,05)$. OEM $=$ orelha de elefante mexicana; $\mathrm{G}$ = genótipo; Icorte = intervalo de cortes; GxIcorte = interação entre genótipo e intervalo de cortes; CV= coeficiente de variação; $p=$ probabilidade. 
quência da IPA 20 comparativamente à Miuda são decorrentes das maiores MF. Ressalta-se ainda que foram elevados os valores de EUA obtidos nesta pesquisa, o que também pode ser explicado pela irrigação, sobretudo pelo método (gotejamento) e manejo da irrigação (fornecimento a cada 15 dias e fertirrigação). A palma forrageira possui o metabolismo MAC para a síntese de tecidos, que envolve a abertura dos estômatos durante a noite, fixando o $\mathrm{CO}_{2}$ neste período quando os ácidos orgânicos são acumulados no citosol. Ou seja, com o fornecimento da água a planta teve aumentada sua taxa de crescimento e, em consequência, usou melhor este recurso para seu desenvolvimento. De acordo com Scalisi et al. (2016) o crescimento do cladódio da palma se dá a partir de $45 \%$ de conteúdo relativo de água no cladódio.

A IPA 20 aos 16 meses à semelhança da Miuda neste mesmo intervalo de corte apresentaram as maiores alturas de plantas. Ainda aos 16 meses, os três genótipos tiveram larguras de plantas similares, embora aos 12 meses após o plantio a Miuda tenha apresentado as plantas mais largas (tabela III).

Em condições de sequeiro no município de Serra Talhada/PE, Silva et al. (2014a) avaliaram a altura das plantas dos genótipos OEM, IPA Sertânia e Miúda cortadas aos 745 dias após o plantio e obtiveram valores de 80,$56 ; 69,44 ; 68,11 \mathrm{~cm}$, respectivamente, em que a altura da palma OEM foi maior que as demais, enquanto a Miúda e a IPA não diferiram entre si. Na presente pesquisa com o aporte adicional de água as alturas das palmas aos 16 meses foram maiores às observadas no estudo de Silva et al. (2014a), além da OEM ter apresentado média inferior à Miúda e IPA 20. Este resultado sugere que a densidade de cultivo e os arranjos utilizados no plantio quanto a espaçamento entre linhas e entre plantas afetam a altura da planta em decorrência da competição por água, nutrientes e luz.

Pinheiro et al. (2014) verificaram que a altura e largura da planta assim como o número de cladódios tiveram alta correlação com o IAC e com a produtividade dos genótipos OEM e Miúda. Estes mesmos autores afirmam que a OEM apresenta crescimento semiaberto que favorece a emissão de cladódios primários, o que pode justificar a MF obtida por este genótipo já aos quatro meses após o plantio, com grande contribuição dos cladódios de primeira ordem. Silva et al. (2014a) relatam que a palma Miúda apresenta crescimento vertical e a maior altura encontrada juntamente com a IPA 20 aos 16 meses indica esta forma de crescimento para este genótipo. A largura da planta é importante para o manejo do palmal e aos 16 meses, as plantas mais largas se aproximaram de $1,10 \mathrm{~m}$. No espaçamento adotado de 2,0 m entre linhas, as larguras das plantas obtidas nesta pesquisa podem permitir a realização dos tratos culturais.

A Miuda apresentou aos 16 meses o maior número de cladódios por planta, enquanto a OEM e a IPA 20 neste mesmo intervalo de corte tiveram maiores pesos médios de cladódios. Os maiores IAC foram obtidos para os genótipos Miuda e OEM aos 16 meses. O avanço no intervalo de corte possibilitou maiores IAC para a OEM e Miuda, enquanto a IPA 20 apresentou semelhante IAC de quatro aos 16 meses (tabela III).

O maior número de cladódios na palma Miúda em comparação com a Redonda e a Gigante foi verificado e relatado por Cavalcante et al. (2014) no município de Frei Paulo/SE. Enquanto as palmas Redonda e Gigante apresentaram 16 e 17 cladódios/planta, respectivamente, a palma Miúda teve 81,5 cladódios aos 24 meses após o plantio e justificaram este resultado à característica de crescimento de plantas do gênero Nopalea com elevado número de cladódios por planta, porém com baixo peso de cladódios. Em média, cada cladódio da IPA 20 se aproximou de $100 \mathrm{~g}$ de MS aos 16 meses, enquanto o cladódio da OEM superou os $100 \mathrm{~g}$ de MS neste mesmo intervalo de corte. O peso do cladódio é outra característica da planta que pode ser influenciado pela densidade de cultivo em decorrência da competição por luz e nutrientes pelas plantas. A alteração nas densidades de cultivos pode levar as plantas forrageiras a buscarem alternativas para a competição por luz e nutrientes como a elevação em altura, por exemplo.

Os genótipos de palma forrageira apresentaram diferentes comprimento, largura e área do cladódio. A OEM e a IPA 20 tiveram os cladódios mais compridos, enquanto a maior largura e a maior área de cladódios foram obtidos pela OEM, ao passo que a Miuda teve os cladódios mais curtos e menos largos em relação às demais (tabela I). Estes resultados indicam que a palma Miuda apresenta como estratégia de crescimento o aumento no número de cladódios a fim de compensar o tamanho e a área de cada cladódio, com consequente aumento no IAC, enquanto a OEM possui menor número de cladódios, porém mais compridos, largos, pesados e com maior área em relação a Miúda e que levou a semelhante valor de IAC para os genótipos

\section{CONCLUSÃO}

O intervalo de corte e os genótipos influenciam as características estruturais e as respostas produtivas da palma forrageira.

\section{AGRADECIMENTOS}

À CAPES, Coordenação de Aperfeiçoamento de Pessoal de Nível Superior pela concessão da bolsa de mestrado.

\section{BIBLIOGRAFIA}

Almeida, J. 2011 . A palma forrageira na região semiárida do estado da Bahia: diagnóstico, crescimento e produtividade. Tese (Doutorado em Ciências Agrárias). Universidade Federal do Recôncavo da Bahia. Cruz das Almas, BA. Brasil.

Cavalcante, L.A.D.; Santos, G.R.A.; Silva, L.M.; Fagundes, J.L. e Silva, M.A. 2014. Respostas de genótipos de palma forrageira a diferentes densidades de cultivo. Pesq Agrop Trop, 44: 424-433.

FAO - Food and Agriculture Organization. 2001. Agroecologia, cultivo e usos da palma forrageira. Traduzido por SEBRAE/PB. SEBRAE/PB. João Pessoa. pp. 36-48.

Farias, I.; Lira, M.A.; Santos, D.C.; Tavares Filho, J.J.; Santos, M.V.F.; Fernandes, A. de P.M. e Santos, V.F. 2000. Manejo de colheita e es- 
paçamento da palma forrageira, em consórcio com sorgo granífero, no agreste de Pernambuco. Pesq Agrop Bras, 35: 341-347.

Nascimento, J.P.; Souto, J.S.; Santos, E.S.; Damasceno, M.M.; Ramos, J.P.F.; Sales, A.T. e Leite, M.L.M.V. 2011 . Caracterização morfométrica de Opuntia fícus-indica sob diferentes arranjos populacionais e fertilização fosfatada. Tecnol Ciên Agropec, 5: 21-26.

Nobel, P.S. 1991. Prediction and measurement of high annual productivity for Opuntia ficu-indica. Agric Meteorol, 56: 261-272.

Nobel, P.S. 2001 . Biologia ambiental In: Barbera, G.; Inglese, P.; Pimienta Barrios, E. (Eds.). Agroecologia, cultivos e usos da palma forrageira. SEBRAE/PB. Paraíba. pp. 36-57.

Pereira, P.C.; Silva, T.G.F.; Zolnier, S; Morais, J.E.F e Santos, D.C. 2015. Morfogênese da palma forrageira irrigada por gotejamento. Rev Caatinga, 28: 184-195.

Pinheiro, K.M.; Silva, T.G.F.; Sousa Carvalho, H.F.; Santos, J.E.O.; Morais, J.E.F.; Zolnier, S. e Santos, D.C. 2014. Correlações do índice de área do cladódio com características morfogênicas e produtivas da palma forrageira. Pesq Agrop Bras, 49: 939-947.

Queiroz, M.G.; Silva, T.G.F.; Zolnier, S.; Silva, S.M.S.; Lima, L.R. e Alves, J.O. 2015. Características morfofisiológicas e produtividade da palma forrageira em diferentes lâminas de irrigação. Rev Bras Eng Agric Amb, 19: 931-938.

Ramírez-Tobias, H.M.; Aguirre-Rivera, J.R. e Pinos-Rodriguez, J.M. 2010. Productivity of Opuntia ssp. and Nopalea sp. (Cactacea) growing under greenhouse hydroponics system. J Food Agric Environ, 8: 660-665. Rego, M.M.T.; Lima, G.F.C.; Silva, J.G.M.; Guedes, F.X.; Dantas, F.D.G. e Lobo, R.N.B. 2014. Morfologia e rendimento de biomassa da palma miúda irrigada sob doses de adubação orgânica e intensidades de corte. Rev Cient Prod Anim, 16: 118-130.

Rocha, R.S. 2016. Caracterização estrutural e produtividade de genótipos da palma forrageira irrigada em diferentes intervalos de corte. Dissertação (Mestrado em Ciência Animal). Universidade Federal do Vale do São Francisco. Petrolina-PE. 44 pp.

Sampaio, E.V.S.B. 2005. Fisiologia da palma In: Menezes, R S.C.; Simões, D.A.; Sampaio, E.V.S.B. (Eds.). A palma no Nordeste do Brasil: conhecimento atual e novas perspectivas de uso. Ed. universitária da UFPE. Recife. Brasil. pp. 43-56.

SAS - Statistical Analysis System. 2002. Sas user's guide: Statistics version 9.1, 4.1. ed. SAS Institute. Cary, NC. 513 pp.

Scalisi, A.; Morandi, B.; Inglese, P. e Bianco, R.L. 2016. Cladode growth dynamics in Opuntia ficus-indica under drought. Environ Exp Bot, 122: 158-167.

Silva, D.J. e Queiroz, A.C. 2002. Análise de alimentos: métodos químicos e biológicos. $3^{a}$ ed. Universidade Federal de Viçosa. Viçosa. Brasil. 235 pp.

Silva, T.G.F.; Araújo Primo, J.T.; Silva, S.M.S.; Moura, M.S.B.; Santos, D.C.; Silva, M.C. e Araújo, J.E.M. 2014a. Indicadores de eficiência do uso da água e de nutrientes de clones de palma forrageira em condições de sequeiro no Semiárido brasileiro. Bragantia, 73: 184-191.

Silva, T.G.F.; Miranda, K.R.; Santos, D.C.; Queiroz, M.G.; Silva, M.C.; Neto, J.F.C. e Araújo, J.E.M. 2014b. Área do cladódio de clones de palma forrageira: modelagem, análise e aplicabilidade. Braz J Agric Sci, 9: 633-641

Silva, T.G.F.; Araújo Primo, J.T.; Morais, J.E.F.; Diniz, W.J.S.; Souza, C.A.A.; Silva, M.C. 2015. Crescimento e produtividade de clones de palma forrageira no semiárido e relações com variáveis meteorológicas. Rev Caatinga, 28: 10-18. 